\title{
Test Excavations at Site 41CD56 Colorado County, Texas
}

Glenn T. Goode

Follow this and additional works at: https://scholarworks.sfasu.edu/ita

Part of the American Material Culture Commons, Archaeological Anthropology Commons, Environmental Studies Commons, Other American Studies Commons, Other Arts and Humanities Commons, Other History of Art, Architecture, and Archaeology Commons, and the United States History Commons

Tell us how this article helped you.

This Article is brought to you for free and open access by the Center for Regional Heritage Research at SFA ScholarWorks. It has been accepted for inclusion in Index of Texas Archaeology: Open Access Gray Literature from the Lone Star State by an authorized editor of SFA ScholarWorks. For more information, please contact cdsscholarworks@sfasu.edu. 


\section{Test Excavations at Site 41CD56 Colorado County, Texas}

\section{Licensing Statement}

This is a work produced for the Texas Department of Transportation (TxDOT) by the report producer. TxDOT and the report producer jointly own all rights, title, and interest in and to all intellectual property developed under TXDOT's contract with the report producer. The report may be cited and brief passages from this publication may be reproduced without permission provided that credit is given to both TxDOT and the report producer. Permission to reprint an entire chapter, section, figures or tables must be obtained in advance from either the Supervisor of the Archeological Studies Branch, Environmental Affairs Division, Texas Department of Transportation, 125 East 11th Street, Austin, Texas, 78701 or from the report producer. 
TEST EXCAVATIONS AT SITE 41CD56

COLORADO COUNTY, TEXAS

By

Glenn T. Goode

Texas

State Department of Highways and Public Transportation Highway Design Division

October 1983 


\section{ABSTRACT}

Site 41CD56 is an aboriginal site located on Crier Creek in northwestern Colorado County, Texas. Testing in October, 1983, revealed that moderate amounts of thermally altered chert/quartzite and lithic debitage were contained in sandy deposits varying from 20 to $110 \mathrm{~cm}$ in depth. Two burned rock accumulations, possibly disturbed hearths, were discovered; but no diagnostic tools or indicators of cultural affiliation were found. 


\section{INIRODUCTION}

Archaeological Site 41CD56 in northwestern Colorado County (Fig. 1) was reported by Mr. Daymond Crawford of the State Department of Highways and Public Transportation (SDHPT) Archaeology Section in September, 1973, and was recommended for test excavations. Testing was conducted by Mr. Glenn T. Goode of the SDHPT Archaeology Section and five members of the local SDHPT office during the period October 4 through 7, 1983, in accordance with the Procedures for the Protection of Historic and Cultural Properties (36 CFR, Part 800). The testing objective was to determine eligibility for nomination to the National Register of Historic Places as prescribed by law. Thanks are extended to District 13 resident engineers Melvin $B$. Bayless and George F. Gold for their cooperation, MS. Alice Lenich and M essrs. Jim Isle, Albert Loehr, George Maxwell, and Hugo Richter were the able field crew. They are to be commended for their assistance. 
This Page Redacted Per THC Policy 


\section{SITE DESCRIPTION}

Archaeological Site 41CD56 is situated on the lower edge of a sandcapped hill near Crier Creek (Fig. 1). The site, dissected by State Highway 71, is $4.7 \mathrm{~km}$ southeast of Ellinger in Colorado County. The area of occupation is a 40-meter wide band which parallels the creek, extending along a north-south axis beyond both fences of the $300-\mathrm{ft}$. right-of-way (Fig. 2).

The site area supports a dense growth of vegetation including several varieties of oak, hickory, elm, hackberry, and cedar. A dense growth of grass and weeds covers the area. The north right-of-way has been bulldozed, with the brush pushed into a pile 100 meters long and 4 to 6 meters wide. The cleared area extends north beyond the right-of-way an additional 70 meters down into the floodplain near the creek. This area is grass-covered pastureland.

A 1-meter wide strip along the south right-of-way fence has also been cleared. The new right-of-way on this side of the project is only 20 meters.

Evidence of aboriginal habitation occurs on the surface in the form of burned rock fragments and lithic debitage. These materials are scattered across an area of some 40 meters width running east to west, and extend beyond the north-south $1 \mathrm{imits}$ of the 300-ft. (91.4-meter) right-of-way. The dense grass cover obscures the cultural material, rather scant over much of the site, except near the right-of-way fences. 


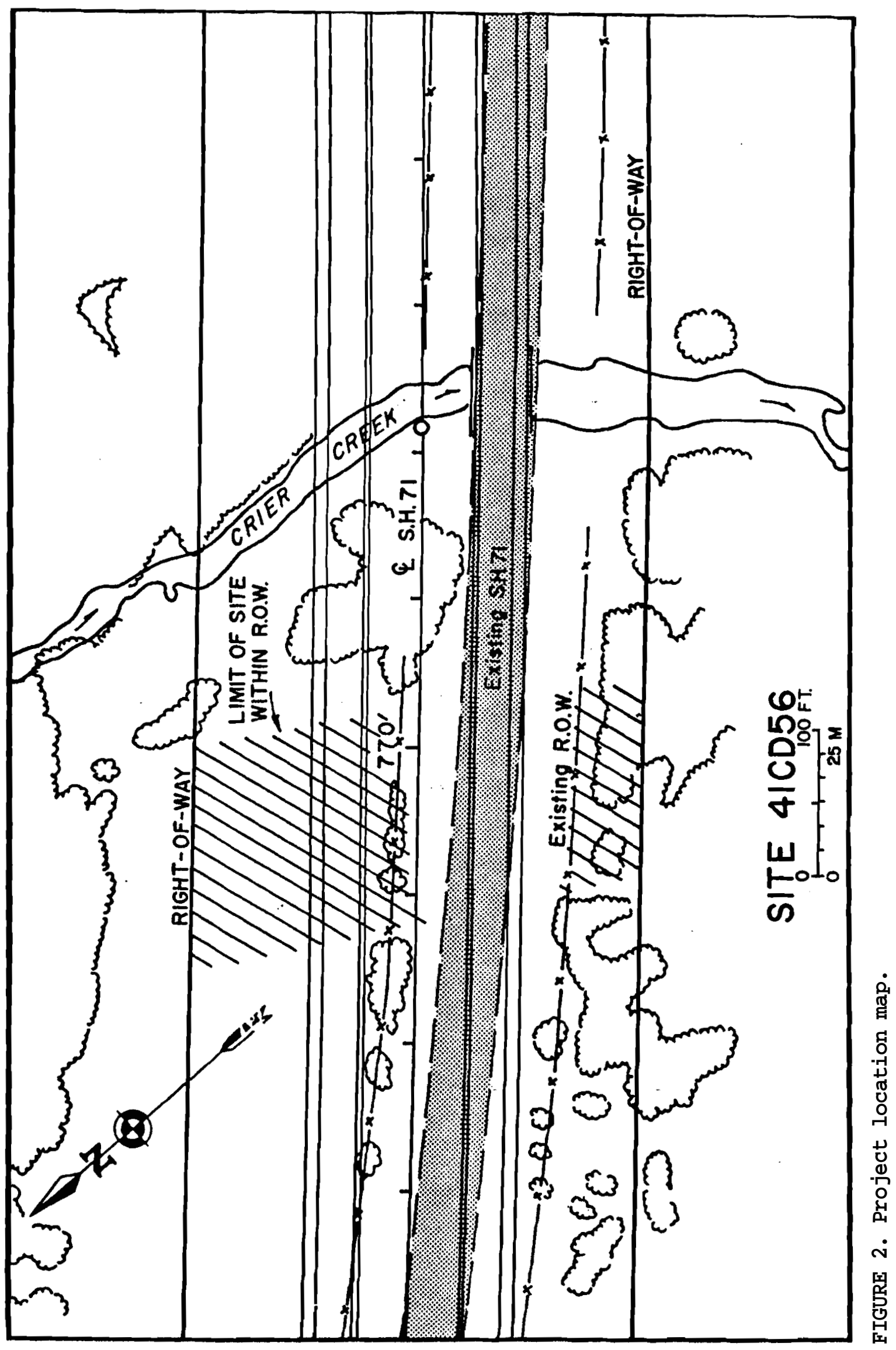


The soil deposit containing cultural materials is a loamy to silty sand. Depth is quite variable. Considerable disturbance of the upper $20 \mathrm{~cm}$ is widespread, with isolated disturbance extending to a depth of $50 \mathrm{~cm}$.

The upper $15 \mathrm{~cm}$ of gray-brown loamy sand contains abundant organic material-(Fig. 3). Roots are numerous below $15 \mathrm{~cm}$ as well, with some tree roots extending to a depth of at least $80 \mathrm{~cm}$. Subsurface evidence of tree clearing in recent years is seen as burned and decomposed roots, some as deep as $50 \mathrm{~cm}$.

Light gray loamy sand extends below the organic zone to 70 or $80 \mathrm{~m}$ depth. This soil is quite loose and homogeneous, replete with evidence of bioturbation.

At 70 to $80 \mathrm{~cm}$ depth, the matrix becomes silty sand, light gray to pale brown in color, and is slightly more compact than the loamy sand. Small pebble chert gravel is widely scattered through the matrix, becoming more abundant with greater depth. Small pebblesize hematite concretions appear near the bottom of this zone, continuing into and becoming more abundant in the underlying zone.

This matrix (at 90 to $120 \mathrm{~cm}$ ) is also silty sand, and with slightly greater silt content is somewhat more compact. As with the hematite concretions, the chert gravel becomes more abundant with depth, and increases to medium pebble size.

A light yellow-brown sandy clay occurs at 120 an and is culturally sterile. 


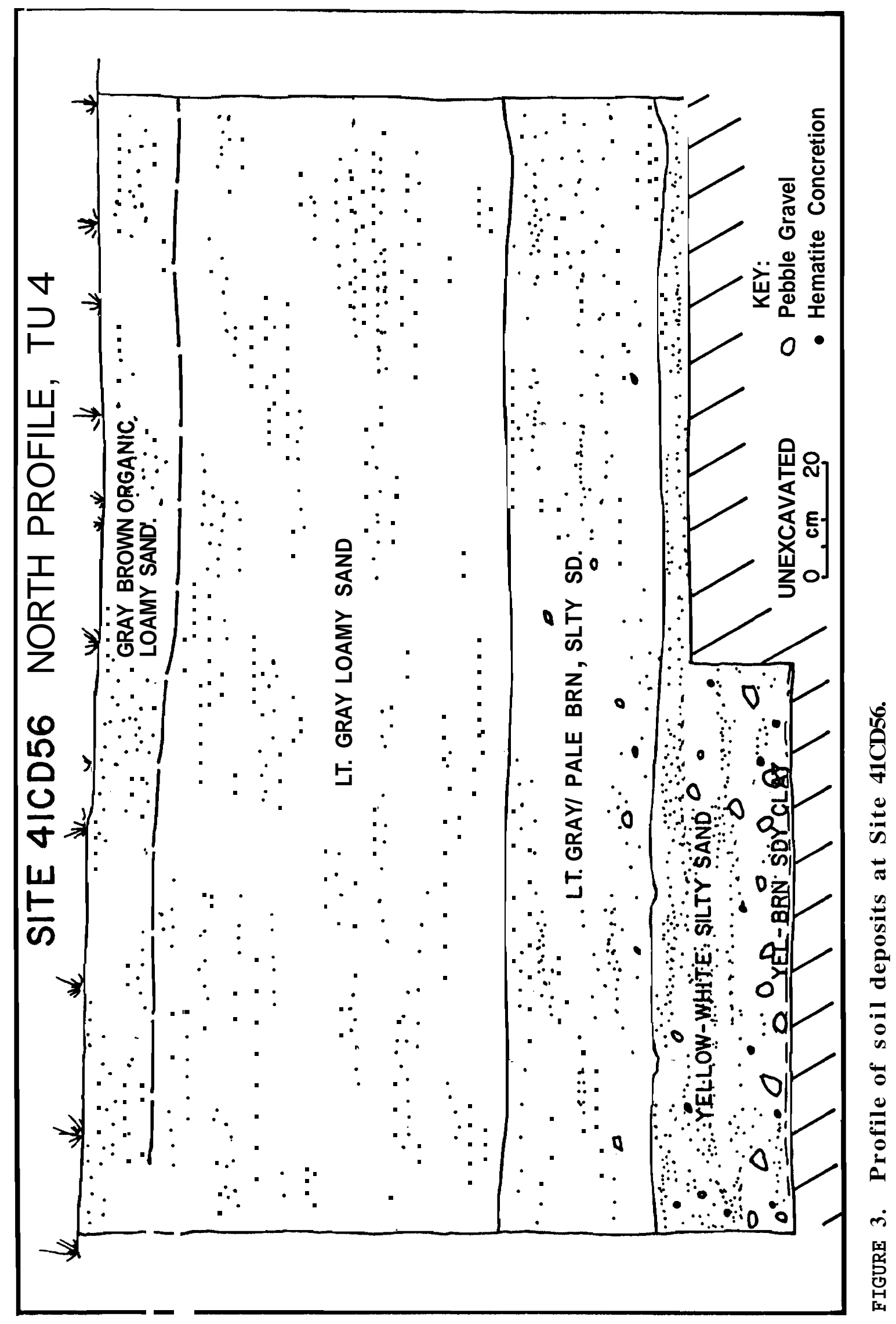




\section{EXCAVATION PROCEDURES}

A single base line (east-west) grid was established near and parallel to the north right-of-way fence. A point $50 \mathrm{~cm}$ south of the north right-of-way at center line station 770+00 was designated W0/S0, and all excavation units were situated west and south of this point. The grid elevation datum (100 meters), established at W22/S9.8, was related to station $770+00$ as well. Grid orientation was east of magnetic north.

Four $1 \times 2$ meter test units were spaced within the area of greatest surface indication and maximum deposit to provide an adequate sample (Fig. 4). Determining the depth and character of the deposit, the extent of the site, and the affiliation of cultural materials were the testing obj ctives. Ten shovel tests were strategically placed in addition to the test units. All units were excavated to basal clay.

Excavation was carried out by shovel, trowel, and smaller tools. All matrix was screened through 1/4 in. hardware cloth, with all artifacts bagged and labeled. Burned rock was separated from artifacts and bagged; then scrutinized for artifacts, recorded by volume, and discarded. 


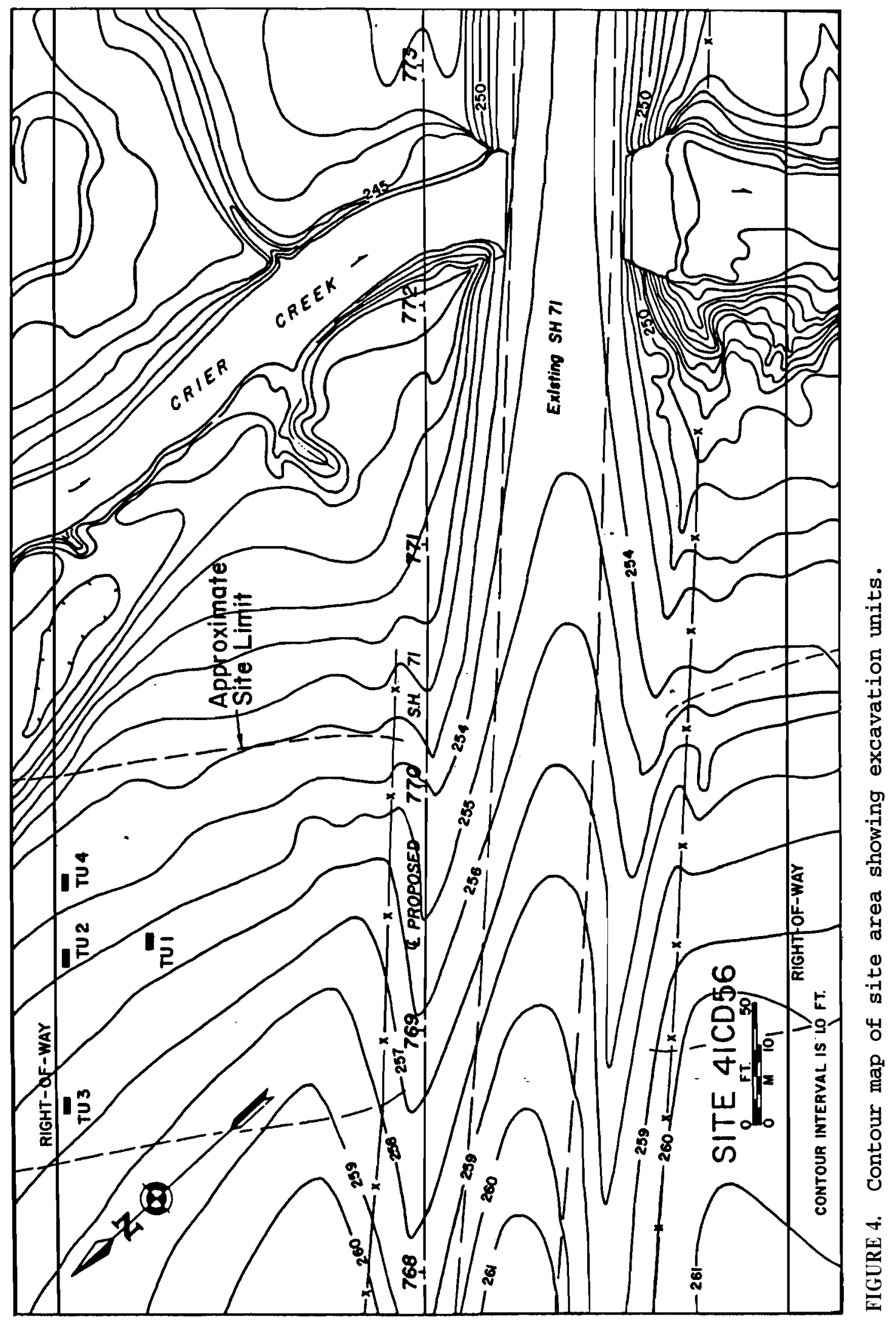


ARTIFACTS

Artifacts are illustrated in Figure 5.

Specimen A

This biface fragment is of such small size that only thickness data is important. It is $6 \mathrm{~mm}$ thick, being the end section of a thin biface. It is within the size range of dart points but appears to be a manufacture failure.

Specimen B

This specimen is a medial section of a thin biface (5 $\mathrm{mm}$ thick). Also within the size range of dart points, this fragment possibly resulted from manufacture failure.

Specimen C

This specimen is a small flake fragment (12 $\mathrm{mm}$ wide and $2 \mathrm{~mm}$ thick). It has minimal pressure flaking along both edges indicating that it might be an arrowpoint preform failure.

Specimen D

This secondary, hard-hammer flake (length, $48 \mathrm{~mm}$; width, $51 \mathrm{~mm}$; thickness, $16 \mathrm{~mm}$ ) had one thin edge modified by short trimming flakes. The trimming produced a steep edge angle of about $60^{\circ}$. This and a downcurved effect of the edge indicate that this piece may have served as a scraper. Evidence of use-wear is minimal.

Specimen E

Also a secondary, hard-hammer flake, this fragment (width, $42 \mathrm{~mm}$; thickness, $16 \mathrm{~mm}$ ) has modification on the same edge (the right). Modification appears as a continuous, shallow nicking; perhaps very shallow trimming 


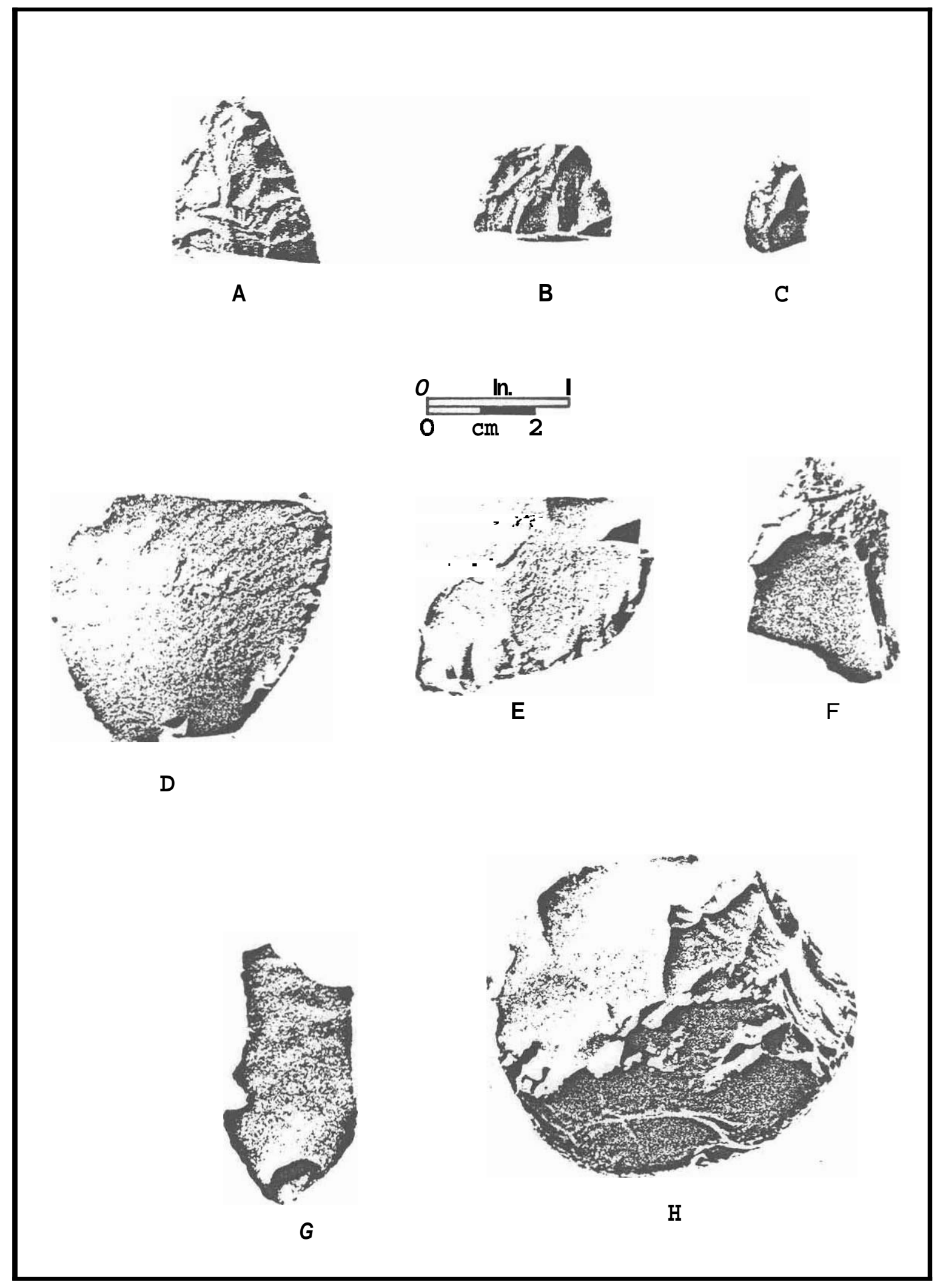

FIGURE 5. A rtifacts. 
is included. The edge is still thin and is quite strong. Minor edge blunting and rounding is present.

\section{Specimen $F$}

This secondary flake (length, $42 \mathrm{~mm}$; width, $27 \mathrm{~mm}$; thickness, $6 \mathrm{~mm}$ ) was produced by a soft hammer. It has steep, continuous chipping (possible trimming) along one thin edge. Light edge rounding exists but function, if any, is unknown.

\section{Specimen G}

This thin, interior flake (length, $46 \mathrm{~mm}$; width, $25 \mathrm{~mm}$; thickness $4 \mathrm{~mm}$ ), probably soft-hammer, has probable use-wear along one sharp edge. Modification exists as continuous nicking, light rounding, and light polish. Light cutting activities are indicated for this piece.

\section{Specimen $\mathrm{H}$}

This specimen is a small core (length, $67 \mathrm{~mm}$; width, $55 \mathrm{~mm}$; thickness $39 \mathrm{~mm}$ ), chipped bifacially from one convex edge. It retains cortex over its rounded, proximal end. Although there is no evidence, it could have served as a small chopper.

\section{Specimen I}

This small biface fragment is not illustrated. It was fairly thin $(7 \mathrm{~mm}$ minimum) and is a manufacture failure. 


\section{LITHIC ANALYSIS}

Thorough analysis was limited to the materials of Test Units 2 and 4, located in the area of maximum cultural deposit. The artifact sample of these two units is $81 \%$ of the total recovered. Test Unit 1 and Test Unit 3 materials were counted and checked for tools, but were not separated into artifact-debitage categories.

Test Units 2 and 4 produced a total of 871 specimens: 844 flakes and flake fragments, 19 cores and core fragments, 3 biface fragments, and 5 possible hammerstones. The inventory of Test Unit 1 is 108 flakes and flake fragments. Test Unit 3 produced 91 flakes and one core fragment. Not a single tool was present in either unit. The total of all artifact classes recovered at Site 41 CD56 is 1071 specimens.

Lithic technology involved the reduction of flint gravel cobbles by free-hand direct percussion techniques. Both hard and soft hammers were employed, the hard hammers being quartzite cobbles present in local gravels. Inferred soft-hammer materials include antler and dense wood. Indication of the pressure-flaking technique exists on at least one modified flake and on one biface fragment. The scant evidence of this technique is a result of the dearth of bifaces and tools in general. A small percentage of debitage has traits of hammer/ anvil direct percussion, but such traits also result from hard-hammer reduction of rounded, hard cortex cobbles.

Discussion of lithic reduction methods frequently involves a linear reduction model. The utility of such models has been ably demonstrated in recent years (Shafer 1973; Patterson 1977). In this case, the'lithic inventory is not sufficiently complex to warrant use of a model. 
Meager though the evidence is, tool production probably followed two basic lines of manufacture typical of the study area. The first method involves cobble reduction into usable flakes. The flakes are then shaped into the desired tool or are used unmodified.

Specimens C through G(Fig. 5) are flake "tools," examples of this process of manufacture. Modification of these flakes is minimal, with trimming appearing as evidence of intentional modification and nicking (Shafer 1973) as incidental and use modification. No flakes of this sample were shaped into formal unifacial tools. Possible use of these flakes is inferred from specimen size and shape, edge angle, and modification type. A binocular microscope was used to detect use-wear patterns.

The second method concerns reduction of a cobble into one primary tool. Usually, such a tool is some form of biface. Evidence of this method is unsubstantiated, unless the bifacial-edge "core" (Fig. 5H) is considered a tool. It is a possible "chopper." The three small final-stage biface fragments provide no clues regarding their origin. Their size is such that production by either method is possible. One point against the cobble-to-biface method is the total lack of early stage biface preforms or failures. Another is the relatively large size of some core fragments and flakes--easily large enough to produce small bifaces.

Although it appears that the major orientation of the lithic technology was quarrying/blank production--judged by the numbers of cores, large flakes, hammerstones, and lack of tools, this is not confidently proven with the limited artifact inventory.

Provenience and categories of artifacts from Test Units 2 and 4 are presented in Table 1. This table was designed strictly for the limited artifact inventory of Site 41CD56, which is almost totally lithic debitage (99\%). Weight in kilograms of thermally altered chert and quartzite is also given. 
The following is the Table 1 legend:

Column 1: size of test unit in meters

Column 2: $10 \mathrm{~cm}$ level number

Column 3: length in mm (rounded off) of flakes greater than $30 \mathrm{~mm}$

Column 4: primary versus secondary flakes

Column 5: hard-hammer, soft-hammer, fragments

Column 6: totals (Flakes)

Column 7: cores and core fragments

Column 8: hammerstones

Column 9 : bifaces

Column 10: modified flakes

Column 11: totals (All materials)

Column 12: burned rock weight in kilograms

The artifact samples from Test Units 2 and 4 are quite similar in all respects. The following discussion compares and combines the data of the two units. Length measurements in millimeters were recorded for flake debitage only. Averaging the samples, 21\% of all flakes are larger than $30 \mathrm{~mm}$; less than 3\% are larger than $50 \mathrm{~mm}$. Five percent of all flakes are primary cortex, and 17.3\% are secondary, an average of 22.5\% flakes with cortex. This flake group is closely tied to the Column 3 data, flakes larger than $30 \mathrm{~mm}$. Many cortex flakes are relatively large--a substantial number of these are hard-hammer flakes.

All flakes were separated into hard-hammer, soft-hammer, and fragments on the basis of platform characteristics. No effort was made to further divide the hard- and soft-hammer categories; given the sample, no useful information would have resulted. The average of hard-hammer flakes for both units is 23.3\%. Soft-hammer flakes, which vary in count by only 1\%, average $27.3 \%$ of the sample. Flakes with platforms only slightly outnumber the flake fragments: $50.6 \%$ to $49.4 \%$.

Nineteen cores and core fragments were recovered. There are some basic similarities among these, but no two are alike. Most had flakes removed multidirectionally, several bidirectionally, and one unidirectionally. Carefully controlled flake production was practiced at times; blade 
TABLE 1. Artifact categories and provenience.

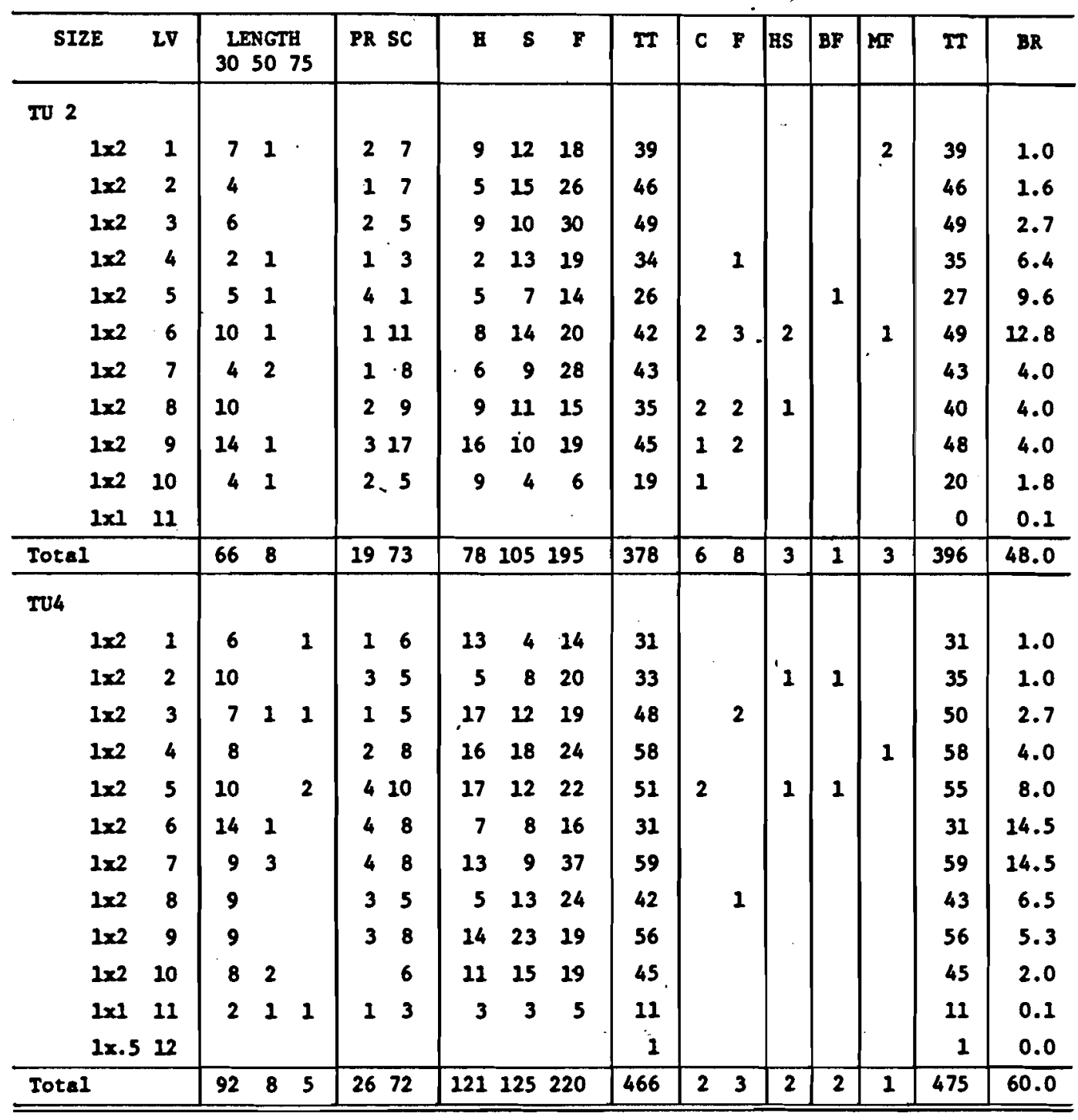


production was not apparent. No specific patterns of reduction can be discerned in the sample. Deep negative removal scars indicate that most initial reduction/decortication was done with hard hammers. Five possible hammerstones occurred in the sample. These are all quartzite cobbles, showing more or less battering on opposite ends.

The nearest raw material source is Crier Creek. Pebble to large cobblesize flint gravel is numerous in the creek bed. Abundant gravel also outcrops across the hill west of the site.

Thermally altered chert and quartzite was relatively abundant, and occurred in roughly equal numbers in Test Units 2 and 4 . Burned rock is present throughout the deposit, widely scattered in most levels. Overall increase in burned rock occurs in Levels 4 through 8 , with two accumulations recorded in Levels 5 and 6. 


\section{FEATURES}

Two irregularly shaped scattered accumulations of burned chert and quartzite were uncovered (Fig. ๑). Rocks range from medium pebblesize fragments to medium cobble size. About 75\% of the rocks are broken. The rocks are closely situated in places, but are widely scattered for the most part. Rocks of both features occurred in Levels 5 and 6, spread at least $15 \mathrm{~cm}$ vertically. A small number of rocks are situated "two dep," indicating that such intentional placement is possible. No evidence of form or pattern exists, and there is no indication of how the rocks were used. Only possible use in hearth activities can be speculated. No charcoal, bone, or stone fools occurred in association with these accumulations. 


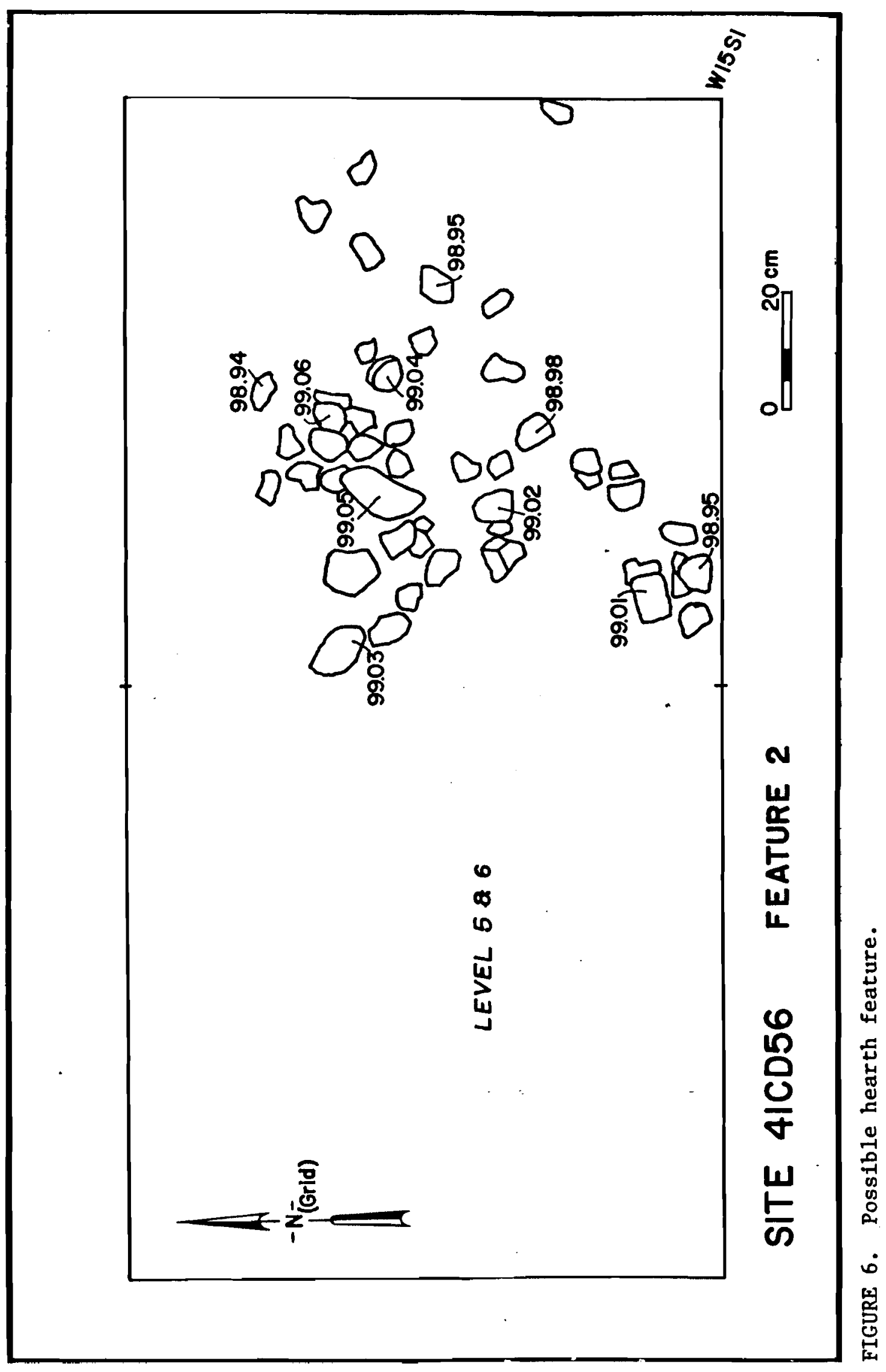




\section{SUMMARY AND RECOMMENDATIONS}

Site 41CD56 is an aboriginal camp and quarry site located on Crier Creek in northwest Colorado County. Apparently, the site was occupied sporadically by hunters/gatherers over an undetermined, but perhaps lengthy, period of time. Test excavations produced a moderate amount of lithic debitage and abundant burned rock. Tools of any form were rare and diagnostic artifacts were not found. Two accumulations of burned chert and quartzite cobbles were uncovered but these "features" lacked structural integrity. If these were constructed hearths, considerable disturbance had destroyed any form or pattern. Small, closely situated groups of rocks were present, with many more scattered about randomly. No organic material or tools were associated, thus the function of Features 1 and 2 remains uncertain.

Although a sizable amount of lithic debitage exists at the site, this material does not contribute significantly to the localprehistory. The lack of tools must be emphasized--less than $1 \%$ of the artifact total are tools and tool failures.

The site area exceeds the right-of-way $1 \mathrm{imits}$ north to south and is 40 meters wide east to west, but only a small area of 6 meters by 30 meters along the north right-of-way has cultural deposits in excess of $40 \mathrm{~cm}$ deep. Subsurface disturbance is extensive in the upper $20 \mathrm{~cm}$ and extends to greater depths frequently. Disturbance of unknown nature and age in the deeper deposits affected Features 1 and 2.

Site 41CD56 is judged as having little potential of making a meaningful contribution to Texas prehistory. The unstratified and culturally undefined deposit, the absence of intact features, and the absence of diagnostic artifacts argue against the significance of this site.

Therefore, Site 41CD56 is not recommended for further testing and should not be considered for inclusion in the National Register of Historic Places. 
REFERENCES CITED

Patterson, Patience E.

1977 A Lithic Reduction Sequence: A Test Case In the North Fork Reservoir Area, Williamson County, Texas.

Bulletin of the Texas Archeological Society 48.

Shafer, Harry J.

1973 Lithic Technology at the George C. Davis Site, Cherokee County, Texas. Ph.D. dissertation, Department of Anthropology, The University of Texas at Austin. 